endeavouring to obtain such dilatation. The difficulties are (1) the tendency to contraction of the pupil due to the low pressure in the eye from leakage through the large wound, and (2) more or less rigidity of the pupil in old people. Using adrenalin, then atropin, then cocain and again atropin, and then repeated cocain instillations a very wide dilatation can be obtained, powerful enough to persist but slightly changed after the cataract incision has been made. At present I am operating thus, sometimes by simple, sometimes by modified simple extraction. Atropin is again instilled twice after operation.

The method has not been very successful in preventing prolapse, but such prolapses as have occurred have been extraordinarily small.

All of these patients upon whom free cocain instillation has been practised with adrenalin, have their heads raised upon pillows or upon an inclined plane until the evening of the operation day, because of the suggestion of tendency to haemorrhage made in the paper already published.

\title{
OBSERVATIONS ON THE WEIGHT, VOLUME, AND ASH OF HUMAN LENSES .
}

\author{
BY \\ F. P. MAYNARD, M.B., F.R.C.S.Eng., \\ L.T.-COLONEL, I.M.S., RETD. \\ Calcutta.
}

IN Volume III of the Transactions of the Ophthalmological Society of the United Kingdom, a paper, by Mr. Priestley Smith, appeared "On the Growth of the Crystalline Lens," in which the weight and volume of lenses removed in their capsules post-mortem, and supposed to be clear, were recorded by means of an apparatus designed for the purpose. The author established the fact that the lens increases in weight and volume throughout life, averaging $1.5 \mathrm{mgm}$. increase in weight and $1.5 \mathrm{c} . \mathrm{mm}$. increase in volume for each year of life from the age of 20 to 70 . Apart from some valuable observations on the specific gravity of the lens, its diameter, the increasing weakness of the hyaloid membrane in older lenses, and the probable cause of hypermetropia acquisita, which are very interesting but do not concern us at present, $\mathrm{Mr}$. Priestley Smith found cataractous opacities in 28 out of the 163 lenses examined. These were found more often, and to a greater degree, as the age of the patients advanced, as one would expect. Two of the eataracts were complete (ripe); of the rest, 22 were cortical, only four being nuclear. In India, the nuclear opacities would have outnumbered the cortical. 
In 1908, Colonel Herbert, in his book on "Cataract Extraction," published the volumes of 15 cataractous lenses he had removed and measured in their capsules in Bombay. In the same year $\mathrm{Mr}$. Priestley Smith very kindly had one of his instruments carefully tested and sent out to me by its maker, Bailey, of Birmingham, and with it I examined some cataracts expressed in their capsules, the results of which are recorded in the following table. As I have practically ceased performing expression of cataract in the capsule and so may have no further opportunity of adding to the observations, it may be as well to publish them now and compare them . with those recorded by Priestley Smith and Herbert.

Each lens was expressed and weighed on a delicate chemical balance. Its volume was next measured by the Priestley Smith apparatus. Its diameter, lying on a table, was recorded, and it was then sent to Captain T. F. Owens, I.M.S., officiating Chemical Examiner to the Government of Bengal, who very kindly incinerated it, and furnished me with the weight of its ash. The temperature and barometric pressure were recorded also, and all the precautions in the measurement of its volume, as laid down, were carefully observed.

It was intended to weigh each patient as well, but unfortunately this was not possible. In three cases there is a note as to size and sex, but no influence of either is observable.

Few as the cases are, the results are of some interest, and in some respects confirm those previously recorded. The most marked feature of all the records is their wide variation. Perhaps in dealing with the examination of such small things as lenses it is to be expected, yet the variations reported by the different observers agree rather remarkably. Thus in clear lenses the extremes of weight recorded were from 151 to $283 \mathrm{mgm}$., and of volume from 139 to $262 \mathrm{c}$. mm. (P. Smith). The variations in cataractous lenses were as follows: weight: from 171 to $277 \mathrm{mgm}$. (P. Smith) 168 to $286 \mathrm{mgm}$. (Maynard) ; volume : from 157 to $263 \mathrm{c.} \mathrm{mm}$. (P. Smith), 153 to 296 c. mm. (Herbert), and 162 to 305 c. mm. (Maynard); and ash : from 0.5 to $7.9 \mathrm{mgm}$. (Maynard). It is interesting to note that Mr. Priestley Smith recorded the greatest weight and the greatest volume in lenses from the same patient, and the lowest weight and the smallest volume in lenses from another individual.

Mr. Priestley Smith observed that lenses in which cataract was beginning were as a rule smaller and lighter than transparent lenses of the same age. This was so even in cases in which the opacities were only very slight. In two cases of ripe cataract he found the opaque lens much smaller and lighter than its less opaque fellow; in one the cornea was also slightly smaller in the eye with the more advanced cataract. The lightest cataractous lens, and the smallest in volume, in my series, was an unripe cataract, the only other 
unripe cataract being also below the average both in weight and volume. The over-ripe lenses were still larger and heavier than the ripe ones. The average of each class was, in weight : unripe-187. ripe-223, over-ripe-235; in volume : unripe-179, ripe-231, over-ripe-283 c.mm. These figures point to a steady increase in weight and volume in Indian cataracts as they ripen and go on to hypermaturity. Eventually, no doubt, a Morgagnian cataract loses in weight and volume as its liquid portions become absorbed.

Age is so impossible to determine with certainty among hospital patients in the East that no observations can be grounded on the ages given. In one case only, No. 7, aged 21, was the age at all certain. In that case the weight and ash were above the average, and the volume was exactly the average. The ash showed great variations, and no definite relation to weight or volume is observable.

TABLE I.

Observations on eleven Cataractous Lenses removed in their Capsules

\begin{tabular}{|c|c|c|c|c|c|c|c|c|c|c|}
\hline 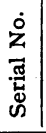 & 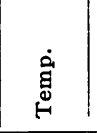 & 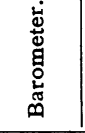 & 它 & 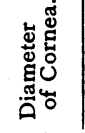 & 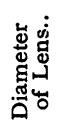 & 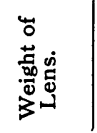 & 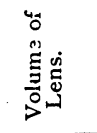 & 站离 & 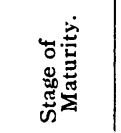 & 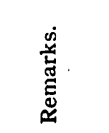 \\
\hline 1 & $85^{\circ}$ & 29.85 & 50 & $\underset{13}{\mathrm{~mm}}$ & mm. & $\begin{array}{l}\text { grm. } \\
0 \cdot 236\end{array}$ & $\begin{array}{l}\text { c.mm. } \\
287 \cdot 04\end{array}$ & $\begin{array}{l}\cdot \mathrm{grm} . \\
0^{\circ} 0006\end{array}$ & over-ripe & - \\
\hline 2 & $89^{\circ}$ & 29.85 & 50 & 11 & - & 0.286 & $268 \cdot 32$ & $0: 0006$ & do. & - \\
\hline 3 & $90^{\circ}$ & $29 \cdot 60$ & 50 & 12 & 8.5 & $0 \cdot 201$ & $234^{\circ} 01$ & 0.0005 & ripe & a big \\
\hline 4 & $92^{\circ}$ & $29 \cdot 60$ & 51 & 11 & 9 & 0.200 & 19032 & 0.0010 & do. & $\begin{array}{l}\text { a small } \\
\text { woman }\end{array}$ \\
\hline 5 & $90^{\circ}$ & $29 \cdot 68$ & 50 & 11.5 & 9.5 & 0.206 & 196.56 & 0.00799 & unripe & - \\
\hline 6 & $89^{\circ}$ & $29 \cdot 77$ & 45 & $12 \cdot 2$ & 9 & $0 \cdot 168$ & $162 \cdot 24$ & 0.0032 & do. & - \\
\hline 7 & $89^{\circ}$ & $29 \cdot 67$ & 21 & 11 & - & 0.252 & $237 \cdot 12$ & 0.0038 & ripe & - \\
\hline 8 & $90^{\circ}$ & $29 \cdot 72$ & 50 & $11 \cdot 25$ & - & $0 \cdot 184$ & $296 \cdot 40$ & 0.0011 & over-ripe & a small \\
\hline 9 & $93^{\circ}$ & $29^{\circ} 68$ & 67 & 11.50 & 9 & 0.235 & 262.08 & 0.0010 & ripe & - \\
\hline 10 & $90^{\circ}$ & 29.57 & 55 & - & 10 & 0.270 & $305 \cdot 76$ & 0.0008 & do. & - \\
\hline 11 & $86^{\circ} \cdot 5$ & $29^{\circ} 66$ & 45 & $9 \cdot 5$ & $9 \cdot 5$ & 0.1815 & $168 \cdot 48$ & 0.0010 & do. & - \\
\hline A & verage & - & - & 11.5 & $\begin{array}{r}9 \cdot 2 \\
- \\
\end{array}$ & $\begin{array}{l}0.2199 \\
=219 \\
\mathrm{mgm} .\end{array}$ & $\begin{array}{r}237 \cdot 12 \\
=237 \\
\text { c. mm. }\end{array}$ & $\begin{array}{l}0.00195 \\
=1.95 \\
\mathrm{mgm} .\end{array}$ & - & - \\
\hline
\end{tabular}

In order to make comparison easier I have worked out, from the figures given in Mr. Priestley Smith's monograph, his results in 
clear and cataractous lenses separately, and tabulated them with Colonel Herbert's and my own results.

\section{TABLE II.}

\section{Comparative Table of Results}

\begin{tabular}{|c|c|c|c|c|}
\hline - & $\begin{array}{c}\text { Average } \\
\text { Weight. } \\
\text { mgin. }\end{array}$ & $\begin{array}{l}\text { Average } \\
\text { Volume. } \\
\text { c.mm. }\end{array}$ & $\begin{array}{l}\text { Average } \\
\text { Ash. } \\
\text { mgm. }\end{array}$ & $\begin{array}{c}\text { Average } \\
\text { Diameter } \\
\text { Lens. } \\
\text { mm. }\end{array}$ \\
\hline Clear Lenses (Priestley Smith) & 237 & 220.4 & - & 9.54 \\
\hline Cataractous Lenses (Priestley Smith) & 224 & 208 & - & 9.45 \\
\hline (Herbert) ... & - & 225.6 & - & - \\
\hline (Maynard)... & 219 & 237 & 1.95 & 9.21 \\
\hline
\end{tabular}

The lesser average weight of our Indian lenses will be noted, also their markedly greater volume. Indian hospital patients in Bengal are as a rule of smaller physique and weight than European, few exceeding $100 \mathrm{lbs}$., and many of the women being as low as 70 or 80 lbs. How far this affects the weight of the lens cannot be stated without further investigation, but it does not appear to affect the volume.

The lens diameter is smaller in Indian cataracts, $9 \cdot 21 \mathrm{~mm}$. compared with 9.45 and $9.54 \mathrm{~mm}$. in European lenses. This smaller diameter, in spite of greater volume, only shows perhaps how unreliable is the measurement of the diameter of a lens when removed from the body. Mr. Priestley Smith's lenses were measured while lying in water, mine lay on a hard flat surface. With the same lens the latter would probably, give the greater diameter.

- Fuchs gives the horizontal diameter of the base of the cornea as $12 \mathrm{~mm}$. and quotes Merkel and Kallius' measurement as $11.9 \mathrm{~mm}$., meaning the diameter of the anterior chamber. Obviously it is very difficult to measure the cornea in the living eye, as the encroachment of the sclera on it varies greatly. Still, my measurements average $11.2 \mathrm{~mm}$. which is not much below 11.9 , and from practical experience of European and Indian eyes, I doubt if the cornea of the latter is much smaller on the average. No relation is traceable between the size of the cornea and the weight or volume of the lens in my cases.

The combined figures indicate:

(1) That great variations in weight and volume are found in both European and Indian lenses;

(2) That in Indian cataracts the ash is very small and varies 
considerably (Roemer states that the lens contains 35 per cent. of solids).

(3) That cataracts in Indians are on the average lower in weight and greater in volume than in Europeans in spite of the heavier physique of the latter.

(4) That cataract in the Indian shows a steady increase in weight and volume as it ripens and passes on into over-ripeness. How cataractous compare with clear lenses in Indians there are no figures to show. In Europeans, Mr. Priestley Smith's statistics prove cataractous to be lighter and of smaller bulk than clear lenses.

\section{ANNOTATIONS}

\section{Ophthalmic Physicians}

A paper was read recently before the Section of Ophthalmology of the Royal Society of Medicine* by Dr. Rayner Batten, in support of his proposal for the appointment of ophthalmic physicians on the staffs of hospitals, to co-operate with ophthalmic surgeons in the care of patients whose ailments are more medical than surgical. No one will dispute Dr. Batten's contention that a considerable proportion of the cases which come under ophthalmic surgeons, both in hospital and private practice, are in need of the advice of a physician rather than that of a surgeon; nor will he deny that while the average ophthalmic surgeon does not possess the requisite medical knowledge to deal with all such cases, the physician to whom he refers the patient not infrequently fails to fill the gap satisfactorily. Indeed, considered as a plea for greater efficiency in dealing with cases whose ocular lesions have a purely medical basis, Dr. Batten's paper will meet with general approval.

Although the writer disclaimed any such intention, there is a real danger that his proposals, if adopted, would lead to the development of two types of practitioners in one special branch of medicine, a contingency greatly to be deprecated. This obvious objection was prominent in the discussion at the Section of Ophthalmology, but it is notable that of the speakers who disagreed with the reader of the paper and his seconder, and who were alive to the inefficiency of existing methods, no one ventured on any constructive criticism, or made any alternative proposals.

That our present arrangements are not ideal, and do not ensure the best possible treatment of ophthalmic medical cases, is indisputable: it is probable, however, that Dr. Batten's paper and 